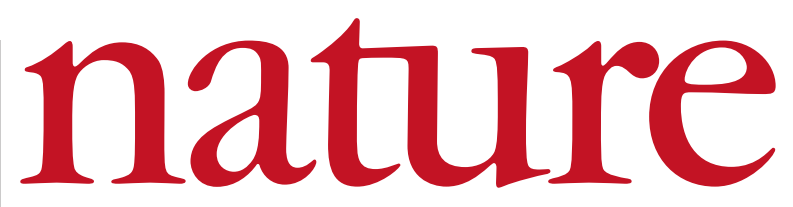

3 June 2004 Volume 429 Issue no 6991

\title{
Proteomic diagnostics tested
}

Concerns about a cancer diagnostics test based on proteomics highlight the threat to public trust in healthcare products where the relevant data are not publicly available — and what can be achieved when they are.

$t$ is easy for critics to slam other scientists who go out on a limb and make big claims for their work. This is the situation facing Emanuel Petricoin and Lance Liotta, two researchers with the US government. The pair led research to develop a ground-breaking diagnostic test for ovarian cancer. Their critics allege that the test is flawed and that corporate entities are trying to rush it to market anyway. The jury is still out on whether the test will prove to be useful in the clinic. But perhaps the most important aspect of the debate is that it would never have arisen if Liotta and Petricoin had not posted their data on the Internet. The episode underscores the crucial importance of readily available public data for scientific progress and, ultimately, for public health.

Liotta and Petricoin believe that their test diagnoses ovarian cancer before the disease progresses to an incurable stage. Their test uses proteomics and involves examining all the proteins in a drop of blood, scanning for a pattern that marks out cancer patients. In a widely hailed study (E. F. Petricoin et al. Lancet 359, 572-577; 2002), they claimed that their proteomic analysis was highly effective. They posted the data on which they based their conclusions on a government website, followed by two more data sets, allowing others to re-analyse their work. Other researchers have done just that, and claim to find technical problems so troubling that they question the conclusions of the original Lancet paper - and even the validity of any diagnostic test based on proteomics (see page 496).

\section{A question of priority}

\section{How to sustain the reliability of the patenting system?}

$\mathrm{T}$ he need for scientists to establish priority for their discoveries is fundamental, but how they do it changes with the years. In the seventeenth century, scientists encrypted their results in anagrams embedded in clearly dated letters sent to colleagues. When Galileo discovered the phases of Venus, he created a Latin anagram whose solution translates as: "The mother of love mimics the Moon's shapes". Desperate to discover his rival's secrets, Johannes Kepler struggled to break the code. He thought he had when he derived a sentence referring to a red spot on Jupiter. Wrong issue, wrong planet and a century ahead of the discovery of the real thing.

Science publishing and patenting nowadays provide more transparent systems for establishing priority, but both are under pressure. In particular, patent offices everywhere have been swamped with applications since the revolutions in information technology, biotechnology and materials sciences, and have struggled to clear mounting backlogs. The European Patent Office (EPO) has coped by recruiting more examiners and by the driving productivity of its staff. But have productivity demands gone too far? Are patent examiners being pushed to work so fast, as they claim (see page 493), that they can't deliver quality patents that would withstand scrutiny?

EPO staff are not complainers by nature, so they should be listened to, particularly at a time when external stakeholders are also voicing concerns. Many observers say that the EPO's commercial
Petricoin and Liotta have defended their methods and the integrity of proteomics as a diagnostic technique for cancer. They also say that a large clinical trial should be performed before the test is marketed to consumers. But the company that worked with the pair on the Lancet paper, Correlogic Systems, has already given two larger companies the rights to market a test called OvaCheck in the United States. Correlogic says that it has worked with its licensees, Quest Diagnostics and the Laboratory Corporation of America, to validate the test and ensure that it will work for women around the country in many different testing conditions. But the companies have not released the data on which they base this conclusion.

If OvaCheck works, it could save many women's lives. But the risks of an imperfect diagnostic test are not slight. Women who receive false positives will undergo needless stress and unnecessary surgery, whereas those who receive false negatives may not receive care in time to save their lives. Before OvaCheck hits the market, Correlogic and its licensees need to publish evidence from a large clinical trial that proves that the test works on samples collected by many different doctors around the country and the world. They should give other scientists the opportunity to examine the data and to send in blinded test samples so that they can determine for themselves whether the test gives accurate results. If it really works, the company should have every confidence that independent researchers will support their determination to speed OvaCheck into the clinic.

orientation overly favours the applicants as customers to be satisfied. Others point to the registration revenues to national patent offices from EPO patents, and say that this factor discourages governments from pressing for quality over quantity.

But what exactly do we mean by patent quality? Any patent must demonstrate novelty, industrial applicability and the involvement of an inventive step. The EPO has a strong reputation in establishing novelty. But it is alleged to be granting some claims for industrial applicability that are inappropriately broad, and granting patents whose inventive step is debatable. Such concerns are themselves hard to test. It would take years to see how many patents are successfully challenged in appeal. Much more useful, and more provocative for the $\mathrm{EPO}$, is the idea that it submit a selection of recently granted patents for external peer review. In the meantime, the concerns are coming from many directions, and confidence in the patenting system is, for the first time, being shaken. Furthermore, patent professionals complain that the quality of incoming applications is now also low.

The EPO's new president, Alain Pompidou, a French biologist, needs to make a clear statement about the office's commitment to quality as soon as he takes over on 1 July. And he must indicate what measures the EPO is going to take to monitor quality. To ignore so much concern would be counter-productive, and would only fuel the smouldering scepticism. Anagrams, anyone? 